\title{
EFFECT OF CONVENTIONAL Vs ENDOSCOPIC MICRODEBRIDER ASSISTED ADENOIDECTOMY ON MIDDLE EAR FUNCTION
}

\author{
Vijendra Shenoy $^{1}$, Oj Giri ${ }^{1}$, Sanchit Bajpai ${ }^{1}$, M.Panduranga Kamath ${ }^{1}$, and Jayashree Bhat ${ }^{1}$ \\ ${ }^{1}$ Kasturba Medical College Mangalore
}

April 28, 2020

\begin{abstract}
Introduction: Adenoidectomy is one of the most commonly performed operation worldwide. Most widely used approach for surgery is conventional curettage method. However, as this method is associated with high incidence of residual adenoid tissue at the end of surgery which results in recurrence of disease, a newer endoscopic microdebrider assisted approach is becoming popular these days. Though various studies have shown its efficacy in more complete removal of adenoids, its functional outcome on middle ear function remains to be explored. Objectives: To compare pre and post operative pure tone audiometric and impedance audiometric analysis following conventional and endoscopic micodebrider assisted adenoidectomy. Materials and Methods: Patients were diagnosed cases of chronic adenoiditis which were divided in groups of 25 each. Patients in first group underwent conventional curettage adenoidectomy while in second group patient underwent endoscopic microdebrider assisted adenoidectomy. Pre and postoperative pure tone and impedance audiometry were performed for all the patients and the outcomes were compared. Results: Endoscopic microdebrider assisted method resulted in better outcomes which were statistically significant as compared to the conventional curettage. Criteria such as hearing threshold ( $\mathrm{p}$ value 0.004 at second follow up), peak pressure ( $p$ value 0.045 at first follow up), tympanogram ( $p$ value 0.016) showed that endoscopic method was better while peak compliance ( $\mathrm{P}$ value 0.340 at first follow up) didn't show any significant difference between the groups. Conclusion: Endoscopic microdebrider assisted method of adenoidectomy has a definite advantage of better visualization and results in more complete removal of tissue and hence results in better improvement in middle ear functions as compared to the conventional curettage.
\end{abstract}

\section{INTRODUCTION}

Enlarged adenoids are an important cause for conditions like serous otitis media, obstructive sleep apnoea, Eustachian tube dysfunction, nasal obstruction and chronic rhinosinusitis. Traditionally the technique of adenoidectomy has been a transoral approach with an adenoid curette or adenotome. As in this approach the adenoid tissue isn't visualized directly, there is always a chance of leaving behind some adenoid tissue. Endoscopic microdebrider assisted technique is most popular these days, it involves direct transnasal visualization of adenoid tissue by a rigid zero degree nasal endoscope and removal of adenoid tissue. This technique offers the advantage of direct visualization of nasopharynx which results in more complete removal of adenoid tissue as well as less chances of injury to the surrounding structures. Various studies have been conducted to compare the conventional curettage technique of adenoidectomy with endoscopic microdebrider technique in terms of parameters such as completeness of removal of adenoid tissue, time required for procedure, amount of blood loss during the procedure, damage to the surrounding structures, post operative pain, recovery time and symptomatic improvement following the procedure. However there are no conclusive studies on whether the type of technique used bears a relationship with the improvement in middle ear function after the surgery. Our study aims at comparing the conventional curettage method of adenoidectomy with endoscopic microdebrider assisted technique in terms of post operative improvement in middle ear function. 


\section{MATERIALS AND METHODS}

This was a prospective study which was conducted among 50 patients of age group 5 to 14 years over two year period Subjects were diagnosed cases of adenoid hypertrophy divided in two study groups of 25 each. In each group, preoperative assessment of middle ear function was done using pure tone audiometry and tympanometry for all the patients. Group 1 patients were treated by a transoral approach with conventional curettage adenoidectomy using St. Clair Thomson's adenoid curette and group 2 patients were treated by endoscopic microdebrider assisted approach, both the nasal cavities were packed with cotton pledgets soaked with $2 \%$ lignocaine and adrenaline for fifteen minutes. Following removal of the pledgets, a $4 \mathrm{~mm}$ Storz rigid nasal endoscope was passed through the nasal cavities to visualize the nasopharynx and the adenoid tissue was removed under direct vision using microdebrider. Post operatively patients were called for two follow up visits, first visit after 1 month and second visit after 2 months of performing the procedure. Repeat pure tone audiometry and tympanometry were conducted at both the follow up visits. All the cases of adenoid hypertrophy which were diagnosed clinically and confirmed by x-ray examination were included for the study. Conditions mimicking adenoid hypertrophy clinically like angiofibroma, nasal Polyposis, nasopharyngeal carcinoma and gross DNS were excluded from the study. Pre and post operative pure tone and impedence audiometric parameters were compared. Statistical analysis of the data was done by using ANOVA (Fischer F test)and student's unpaired T test. A statisiscal package, SPSS 17 was used for analysis. A $\mathrm{p}$ value of less than 0.05 was considered significant.

\section{RESULTS}

Conventional adenoidectomy was performed in 25 patients and endoscopic microdebrider assisted adenoidectomy was performed in 25 patients. Both the groups were compared in terms of various audiological parameters.

\section{(i) Hearing Threshold}

42 ears $(84 \%)$ in conventional adenoidectomy group had hearing thresholds higher that $15 \mathrm{~dB}$ while 40 ears $(80 \%)$ in endoscopic microdebrider assisted group had hearing thresholds above $15 \mathrm{~dB}$. p value for preoperative comparison between the groups is 0.604 which is not statistically significant. After $1^{\text {st }}$ follow up the patients with abnormal hearing thresholds were $30(60 \%)$ in conventional curettage group and 20 (40\%) in endoscopic approach group. P value for comparison between these groups is 0.047 which shows that the difference is statistically significant. At second follow up, 12 ears $(24 \%)$ in conventional curettage group

had abnormal hearing thresholds while in endoscopic microdebrider group only 2 ears (4\%) had hearing thresholds above $15 \mathrm{~dB}$. P value for comparison is 0.004 which is highly significant. (Table 1)

\section{(ii) Peak Compliance}

At presentation, 21 ears (42\%) in conventional curettage had abnormal peak compliance while 24 ears (48\%) in endoscopic microdebrider assisted group had an abnormal peak compliance. Comparison between the groups yielded a p value of 0.549 which is not statistically significant. At first follow up 7 ears(14\%) in conventional group and 4 ears (8\%) in endoscopic microdebrider assisted group had abnormal peak compliance ( $\mathrm{p}$ value $0.340=$ not significant). At second follow up, 4 ears $(8 \%)$ in conventional curettage group and 3 ears $(6 \%)$ in endoscopic microdebrider assisted group had abnormal compliance ( $\mathrm{p}$ value $0.697=$ not significant). (Table 2)

\section{(iii) Peak Middle Ear Pressure}

Out of 50 ears in conventional curettage group, 38 ears $(76 \%)$ had impaired peak middle ear pressure at presentation while in endoscopic microdebrider assisted group, 36 ears (72\%) had abnormal pressure. Comparison showed a $\mathrm{p}$ value of 0.650 which shows that there was no significant difference in the groups. At first follow up, 15 ears (30\%) in conventional curettage group and 7 ears in endoscopic microdebrider assisted group had abnormal peak middle ear pressure ( $\mathrm{p}$ value $0.045=$ significant $)$. After $2^{\text {nd }}$ follow up, 6 ears $(12 \%)$ in conventional curettage group and 4 ears (8\%) in endoscopic microdebrider assisted group had abnormal peak pressures (p value $0.507=$ not significant). (Table 3) 


\section{(iv) Tympanogram}

In conventional curettage group, 38 ears (76\%) and in endoscopic microdebrider assisted group 39 ears (78\%) had a B or C type of curve at presentation (p value $0.813=$ not significant). After first postoperative follow up, 20 ears (40\%) in conventional group and 9 ears in endoscopic microdebrider assisted group had a B or $\mathrm{C}$ type of curve (p value $0.016=$ statistically significant). At the time of $2^{\text {nd }}$ follow up, 10 ears $(20 \%)$ in conventional group and 4 ears (8\%) in endoscopic microdebrider assisted group had a B or C type of curve ( $\mathrm{p}$ value $0.085=$ not significant $)$. (Table 4$)$

\section{DISCUSSION}

Adenoidectomy has been the hallmark treatment in children suffering from otitis media with effusion since past many decades ${ }^{(1)}$. There have been various expansion in research in the field of adenoidectomy and its outcomes, but sparse literature is available studying the outcome of adenoidectomy on middle ear functions. There is a paucity of literature available in testing middle ear functions post adenoidectomy and thus we conducted this study to critically appraise the results comparing the middle ear functions post conventional and endoscopic microdebrider assisted adenoidectomy.

Adenoid hypertrophy in children is the most common cause of eustachian tube blockage leading to fluid collection in the middle ear i.e otitis media with effusion leading to derangement of middle ear functions and various modalities of treatment have been in use since time immemorial in treating it.

In a recent Cochrane review by Van den Aardweg et al. [2] they reported that there is a significant benefit of adenoidectomy in the resolution of middle ear effusion in children with OME, but the benefit to hearing is small and the effects on changes in the tympanic membrane are unknown.

Coyle et al (3) also concluded in his study that adenoidectomy is a useful procedure for correction of medically resistant chronic OME and should be considered as the first line procedure when surgical treatment is chosen.

However the dissatisfaction over the widely used conventional curettage adenoidectomy since many years has prompted the use of endoscopic assisted powered shaver adenoidectomy with microbebrider in recent times.

Setliff and parsons introduced microdebrider use in nasal surgery in 1994. The unique design equipped with powered shaver, continuous irrigation device and suction port makes this instrument superior in clearing tissue from the field under direct vision with minimal complications.

Stainslaw et al(4) found that tissue dissection was more complete and of appropriate depth with a microdebrider as compared to the depth being too shallow in conventional method leaving behind significant tissue post procedure.

Various studies conducted by Murray et al. Rodigruez et al. Costantini et al. proved that endoscopic assisted powered shaver adenoidectomy is more effective in cleaning adenoid tissue under direct visualization; thus requiring less operating time, causing less blood loss, and providing more complete removal of the adenoid tissue and less post-operative pain. ( 5,6 )

By using endoscopic assisted adenoidectomy with a microdebrider, the adenoid remnants along the superior portion of the nasopharynx, the choanae and the peritubal region, can be clearly visualized easily and thus removed completely. Moreover, the likelihood of damage to the Eustachian tube and/or to the pharyngeal muscles is reduced, thereby reducing the post-operative scarring. Hemorrhage can also be effectively controlled by direct identification of the bleeding points $(7,8)$.

Tympanometry has been a novel approach in studying the function of middle ear including middle ear pressures, volume and compliance. This study also states the use of these modalities in testing middle ear function. According to Renvall et al (9) stapedial reflex is considered too sensitive to be used as a screening test in the diagnosis of OME thus we excluded it from our criteria.

The patients included in our study showed a significant improvement in hearing thresholds post endoscopic microdebrider assisted adenoidectomy resulting in only $4 \%$ patients with abnormal hearing threshold in 
comparison to the conventional method being $24 \%$ ( $\mathrm{p}$ value 0.004 ). There was not much statistical difference seen in the peak compliance comparing the two groups but however the peak middle pressures were found to be significantly improved post surgery in children undergoing endoscopic microdebrider assisted adenoidectomy compared to conventional method .

The initial preoperative tympanograms of patients presenting showed $\mathrm{B}$ and $\mathrm{C}$ type of curves which were found to have significantly improved (normal A type) in children who underwent endoscopic microdebrider assisted adenoidectomy in our study.

Similar studies have been conducted in evaluating the conversion rates of tympanograms by Sarafoleanu et al. in 2010 which revealed a type-B curve in $41 \%$ of cases, compared with type- $\mathrm{A}$ in $22 \%$ and type-C curve in $37 \%$ of cases. Re-evaluation performed after 4 weeks of surgery (classical adenoidectomy) in their study also documented very good relief of disease on subjective as well as objective evaluation (10). Another study by Mori et al. in 1980 also observed a type-B tympanogram in $50 \%$ of cases preoperatively with post-operative conversion to type-A. (11)

Thus the clinical outcome and improvement in middle ear functions was found to have improved drastically in the children who underwent microdebrider assisted adenoidectomy as compared to the conventional method

\section{Conclusion:}

Adenoidectomy in hypertrophied adenoids with OME is simple and effective procedure in the resolution of OME and improvement in hearing postoperatively. Visual aided clearance of adenoids using microdebrider with complete clearance of tissue over the ET opening has led to a major advantage of using it over the conventional method. Middle ear function tests, pre and post operatively not only give a fair idea about the operative outcome but also help in following up the patient and the disease process. Microdebrider assisted adenoidectomy as compared to the conventional method has proven to have promising results with a significant improvement in middle ear functions as seen in our study.

\section{References}

1. Cummings - Andrew F. Inglis Jr. George A. Gates Cummings Otolaryngology - Head and Neck surgery,4th edition, Elsevier Mosby, 2005, vol - 4,Pg - 4445-4464

2. Van den Aardweg MT, Schilder AG, Herkert E, Boonacker CW, Rov $\neg$ ers MM. Adenoidectomy for otitis media in children. Cochrane Daᄀtabase Syst Rev. 2010 Jan;(1):CD007810.

3. Coyle PC. Croxford R, MC Isaac W, Feldman W, Friedberg J. The role of Adjuvant adenoidectomy \& tonsillectomy in the out of the insertion of tympanostomy tube. N Engl J Med 2004; 344: 1188-95.

4. Stanislaw P, Koltai PJ, Feustel PJ. Comparison of power-assisted adenoidectomy vs adenoid curette adenoidectomy. Arch Otolaryngol Head Neck Surg. 2000 Jul;126(7):845-9.

5. Clemens J, McMurray JS, Willging JP. Electrocautery versus curette adenoidectomy: comparison of postoperative results. Int J Pediatr Otorhinolaryngol.1998;43(2):115-22.

6. Murray N, Flitzpatrick P, Guarisco JL. Powered Partial Adenoidectomy. Arch Otolaryngol Head and Neck Surg. 2002;128(7):792-6.

7. Becker SP, Roberts N, Coglianese D. Endoscopic adenoidectomy for the relief of serous otitis media. Laryngoscope.1992;102:1379-84.

8. Rodriguez K, Murray N, Guarisco JL. Power assisted partial adenoidectomy. Laryngoscope. 2002; 112:26-8.

9. N A Blac et al. randomised controlled trial of surgery for glue ear, BMJ Vol 30016 June 1990;300:1551-6

10. Sarafoleanu C, Enache R, Sarafoleanu D. Eustachian Tube Dysfunction of Adenoid Origin. Therapeutics, Pharmacology and Clinical Toxicology. 2010;14(1):36-40.

11. Mori H, Kitahara K, Kita M, Takahashi H, Nakai Y. Analysis of tympanograms in relation to the treatment of adenoid vegetation. Nippon Jibiinkoka Gakkai Kaiho.1980;83(4):415-23.

Tables 
Table 1 : Comparison between the groups in terms of hearing thresholds

\section{Hosted file}

image1. wmf available at https://authorea.com/users/307682/articles/438681-effect-of-conventionalvs-endoscopic-microdebrider-assisted-adenoidectomy-on-middle-ear-function

Table 2: Comparison between the Groups in terms of compliance

\section{Hosted file}

image2.wmf available at https ://authorea.com/users/307682/articles/438681-effect-of-conventionalvs-endoscopic-microdebrider-assisted-adenoidectomy-on-middle-ear-function

Table 3 : Comparison between the groups in terms of peak pressure

\section{Hosted file}

image3.wmf available at https://authorea.com/users/307682/articles/438681-effect-of-conventionalvs-endoscopic-microdebrider-assisted-adenoidectomy-on-middle-ear-function

Table 4: Comparison between the groups in terms of tympanogram

\section{Hosted file}

image4. wmf available at https://authorea.com/users/307682/articles/438681-effect-of-conventionalvs-endoscopic-microdebrider-assisted-adenoidectomy-on-middle-ear-function 